\title{
Ossifying fibroma - diagnosis, treatment, and follow-up: case report and literature review
}

Fernando de Oliveira Andriola ${ }^{\mathrm{a}}$, Leonardo Matos Santolim Zanettini ${ }^{\mathrm{a}}$, Bernardo Ottoni Braga Barreiro ${ }^{\mathrm{a}}$, Valéria Rodrigues Saraivab ${ }^{b}$ Fábio Luiz Dal Moro Maitoc ${ }^{\circ}$ Guilherme Genehr Fritscher ${ }^{c}$, Cláiton Heitz Rogério Miranda Pagnoncelli ${ }^{d}$

\begin{abstract}
OBJECTIVE: This article presents a case of ossifying fibroma (OF), including its diagnosis, treatment, and 15-month clinical and radiographic follow-up as well as a review of the literature about this pathology.

CASE REPORT: A routine panoramic radiograph of a $27-y e a r-o l d$, systemically healthy, white woman revealed a radiolucent lesion with well-defined sclerotic margins of approximately $3 \times 2 \mathrm{~cm}$ in the mandible. The histopathological diagnosis revealed it was an OF. Lower Right Canine and Lower Right First Premolar teeth were endodontically treated for later surgical removal of the tumor. There was no history of trauma in the region.

CONCLUSION: OF is a benign fibro-osseous tumor of the craniofacial bones commonly involving the jaws, especially the mandible. The diagnosis is based on a combination of clinical, radiographic and histologic criteria. Conservative treatment is an effective option that reduces morbidity and simplifies postoperative rehabilitation. We emphasize the importance of properly documenting individual cases and interpreting postoperative radiographic images along with the patients in order to avoid possible confusion between areas of bone repair and of potentially suspicious lesions in the future.
\end{abstract}

Key words: Surgery, Oral; Pathology, Oral; Fibroma, Ossifying

\section{Fibroma ossificante - diagnóstico, tratamento e acompanhamento: relato de caso e revisão da literatura}

\section{RESUMO}

OBJETIVO: Este artigo apresenta um caso de fibroma ossificante (OF), incluindo seu diagnóstico, tratamento e acompanhamento clínico e radiográfico de 15 meses, bem como uma revisão da literatura sobre esta patologia. RELATO DO CASO: Uma radiografia panorâmica de rotina de uma mulher branca de 27 anos, sistemicamente saudável, revelou uma lesão radiolúcida com margens escleróticas bem definidas de aproximadamente $3 \times 2 \mathrm{~cm}$ na mandíbula. O diagnóstico histopatológico revelou que era um FO. O Canino Inferior Direito e o Pré-Molar Inferior Direito foram tratados endodonticamente para posterior remoção cirúrgica do tumor. Não havia história de trauma na região.

CONCLUSÃO: O FO é um tumor fibro-ósseo benigno dos ossos craniofaciais que comumente envolve os ossos maxilares, especialmente a mandíbula. O diagnóstico é baseado em uma combinação de critérios clínicos, radiográficos e histológicos. O tratamento conservador é uma opção eficaz que reduz a morbidade e simplifica a reabilitação pós-operatória. Ressaltamos a importância de uma adequada documentação dos casos, bem como do esclarecimento sobre a evolução das imagens radiográficas pós-operatórias junto aos pacientes, de modo a evitar possíveis confusões entre as áreas de reparo ósseo e suspeitas de novas lesões no futuro.

Palavras-chave: Cirurgia Bucal; Patologia Bucal; Fibroma Ossificante

\author{
a Master's student, PUCRS, Porto Alegre, RS, Brazil \\ ${ }^{\mathrm{b}}$ Graduate Student, PUCRS, Porto Alegre, RS, \\ Brazil \\ PhD, Associate Professor, PUCRS, Porto Alegre \\ RS, Brazil \\ ${ }^{d}$ PhD, Full Professor, PUCRS, Porto Alegre, RS, \\ Brazil
}

Correspondence: Fernando de Oliveira Andriola

Received: January 31, 2017 Accepted: July 28, 2017

Conflict of Interests: The authors state that there re no financial and personal conflicts of interest that could have inappropriately influenced their work.

Copyright: (c) 2017 Andriola et al licensee EDIPUCRS

This work is licensed under a Creative Commons Attribution 4.0 International License. 


\section{INTRODUCTION}

Ossifying fibroma $(\mathrm{OF})$ is a true neoplasm of mesenchymal origin with a significant growth potential. This benign fibroosseous tumor is most commonly found in the mandibular molar/premolar region and occurs predominantly in the third and fourth decades of life, affecting women more than men [1-6]. OF consists of intraosseous fibrous tissue that exhibits varying degrees of cellularity and contains mineralized material. It appears as a well-circumscribed lesion that may or may not be surrounded by a fibrous capsule $[1,2,4]$.

We report a case of ossifying fibroma in a 27 -yearold female patient, including its diagnosis, treatment, and 15-month clinical and radiographic follow-up as well as a review of the literature on this condition.

\section{CASE DESCRIPTION}

A routine panoramic radiograph of a 27-year-old, systemically healthy, white woman revealed a radiolucent lesion with well-defined sclerotic margins of approximately $3 \times 2 \mathrm{~cm}$ in the apical region spanning \#42 to \#45. There was no history of trauma in the region. On clinical examination, the teeth showed a negative response to percussion and sensitivity testing, and no pain was reported. Intraoral examination revealed an intact mucosa in the affected area and slight expansion of the buccal cortical plate. A diagnostic hypothesis of giant cell lesion was made.

Laboratory findings (complete blood count, platelet count, blood glucose, erythrocyte sedimentation rate [ESR], activated partial thromboplastin time [APTT], prothrombin time $[\mathrm{PT}]$, and phosphorus, calcium, alkaline phosphatase, parathyroid hormone $[\mathrm{PTH}]$, urea, and creatinine levels) were within normal limits, and hyperparathyroidism was ruled out.

An incisional biopsy of the lesion was performed at the Department of Oral and Maxillofacial Surgery of the institution. A solid fragment with the consistency of cancellous bone was sent for histopathological examination and the possibility of fibrous dysplasia was considered. The histopathological diagnosis, however, was an OF.

Teeth \#43 and \#44 were endodontically treated for later surgical removal of the tumor. The teeth were splinted using orthodontic wire and brackets and a CBCT scan of the affected area was obtained (Figure 1). Surgery was then performed under general anesthesia via an intraoral approach.

An L-shaped incision was made between \#41 and \#42, a mucoperiosteal flap was raised, and osteotomy of the buccal cortical bone was performed, followed by curettage of the lesion (Figure 2). The surgical specimen (reddish in color with a consistency similar to cancellous bone) was sent for histopathological examination, which confirmed the diagnosis of OF (Figure 3).
The patient has been followed clinically (Figure 4) and radiographically (Figure 5) for 15 months. In the first postoperative week, there was slight edema, no pain or bleeding, and mild trismus. Teeth $\# 42$ and $\# 45$ responded positively to pulp vitality testing at 1 month and 6 months after surgery. The patient reported paresthesia in the region of the mental foramen up to 6 months after surgery. At the time of the last follow-up visit, 15 months after surgery, radiograph revealed bone healing without signs of recurrence and an almost imperceptible buccal scar (Figure 5). The patient is currently in good clinical condition.

Written informed permission was obtained from the patient to publish this case report. The study was approved by the Research Ethics Committee of the institution.

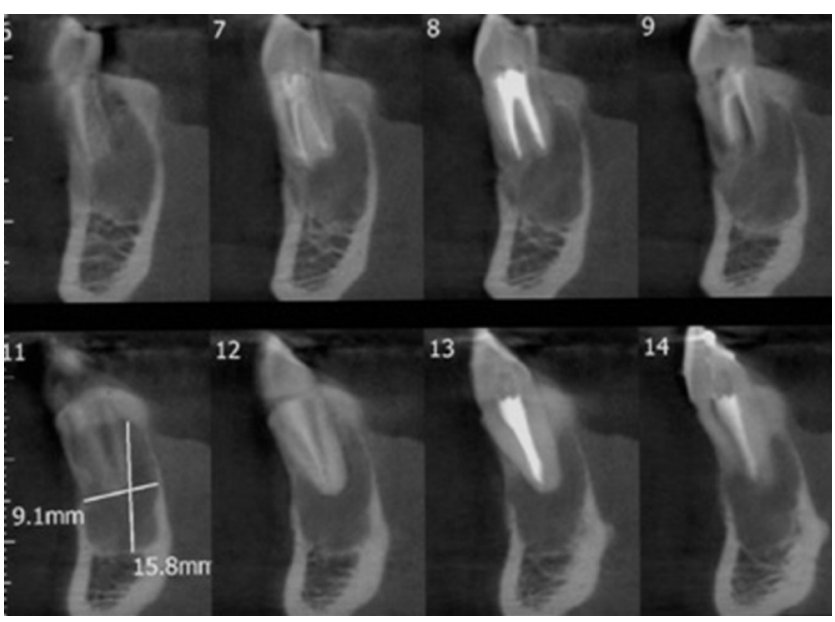

Figure 1. Preoperative CBCT. Sagittal section showing the buccolingual extent of the lesion and the two endodontically treated teeth (\#43 and \#44)

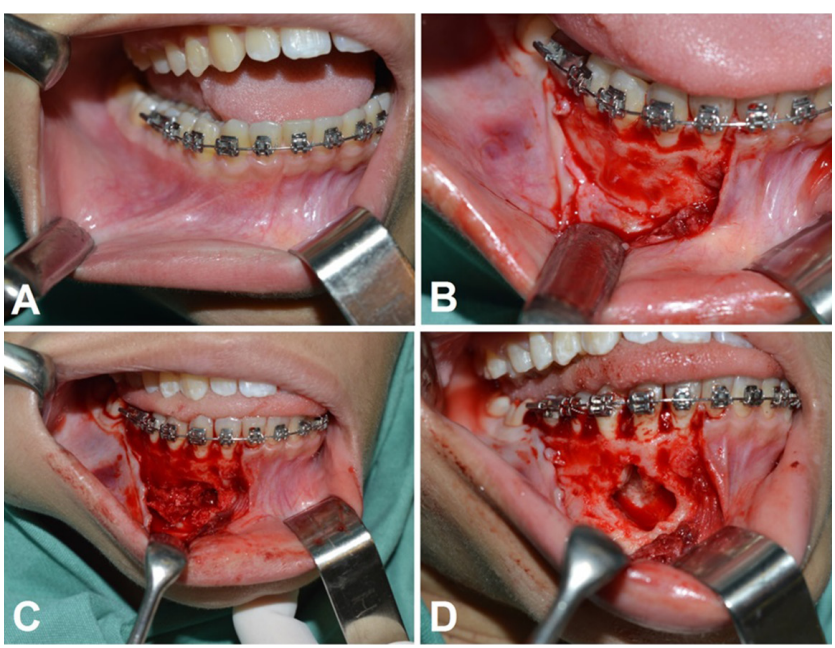

Figure 2. (A) Preoperative intraoral appearance. (B) Mucoperiosteal flap elevation. (C) Specimens obtained during curettage of the lesion. (D) Bone defect caused by ossifying fibroma after complete curettage of the lesion 

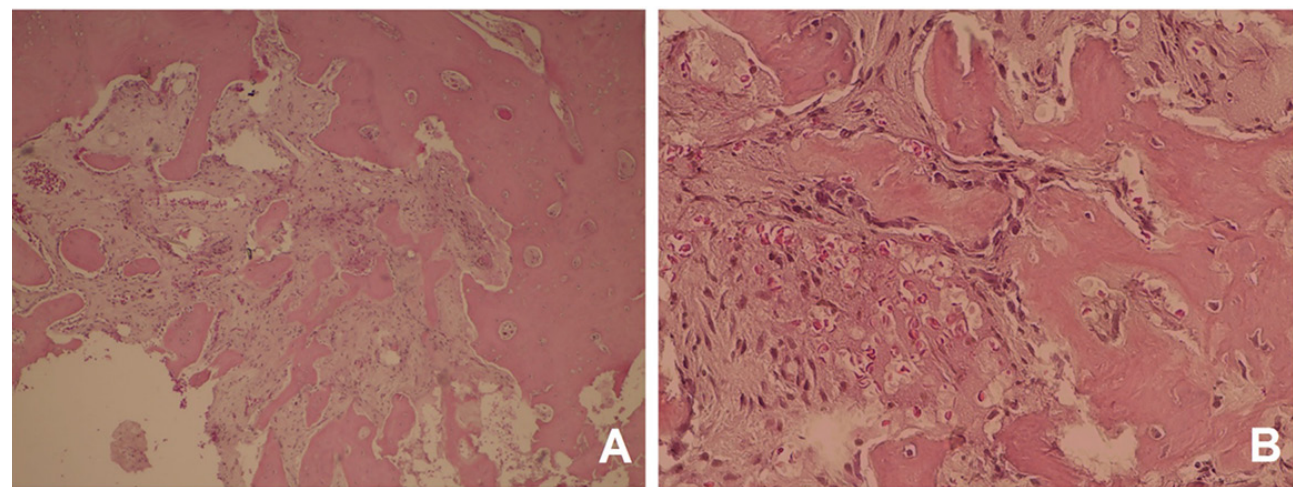

Figure 3. (A) Irregular, rounded bone formation surrounded by cellularized fibrous connective tissue (hematoxylin-eosin $[\mathrm{HE}], \times 40$ ). (B) Osteoblastic rimming and irregular cell-poor bone tissue with few osteocytes. The stromal cells are arranged in circular formations of osteoblasts parallel to the bone spicules, a feature that differentiates ossifying fibroma from fibrous dysplasia $(H E, \times 200)$
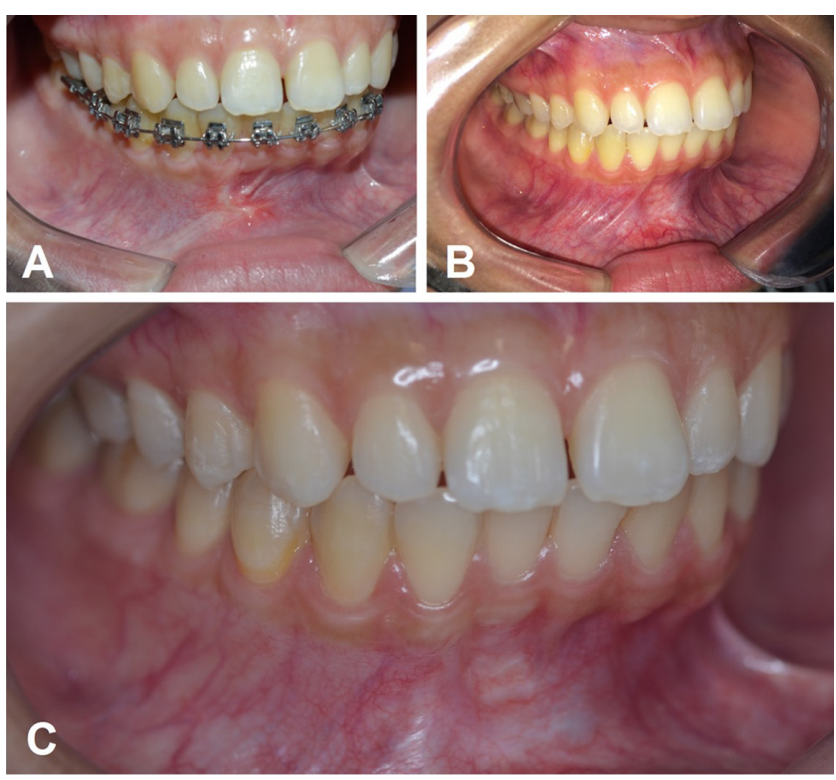

Figure 4. Clinical follow-up: (A) at 1 month; (B) at 10 months; (C) at 15 months

\section{DISCUSSION}

OF is a benign, slow-growing fibro-osseous neoplasm of the jaws with a significant growth potential that contains fibrous tissue and a mixture of bone trabeculae and cementum-like spherules $[7,8]$. The condition refers to a process in which normal bone is replaced with fibroblasts and collagen fibers containing varying amounts of mineralized material [2].

Previously, the name given to the lesions depended on the type of calcified tissue formed, and lesions were classified as $\mathrm{OF}$, cementifying fibroma or cemento-ossifying fibroma when they formed bone tissue, cementum-like

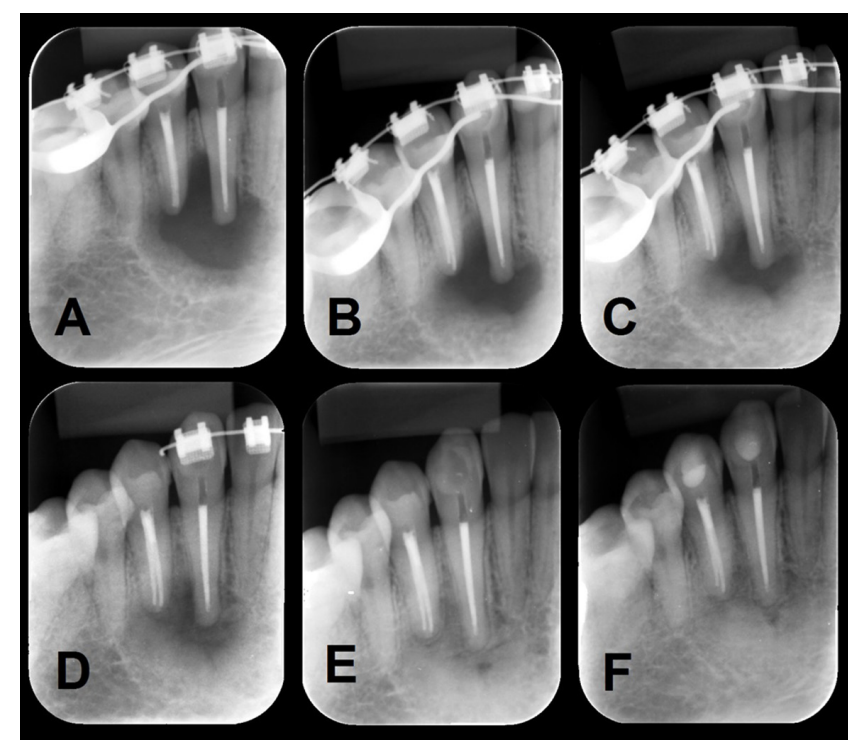

Figure 5. Radiographic follow-up (periapical radiographs): (A) at 15 days; (B) at 45 days; (C) at 3 months; (D) at 6 months; (E) at 10 months; (F) At 15 months

tissue or a mixture of both, respectively. Currently, all types are referred to as OF, regardless of the type of material within the lesion. Some authors even consider the cementum-like material to be a mere variation of bone tissue $[7,8]$.

For a long time, the nomenclature and classification of this condition were considered unclear. However, currently, OF has two variants: true OF and juvenile OF [1]. The juvenile OF is usually found in young patients (children and adolescents aged $\leq 15$ years) and is known to be more aggressive, growing faster than $\mathrm{OF}$ with greater destructive power. This more aggressive variant is further subdivided into trabecular and psammomatoid juvenile $\mathrm{OF}$ - the first is 
associated with pediatric patients and usually involves the maxilla, while the second is associated with adolescents and adults and usually involves the orbit and paranasal sinuses [1-3]. True OF is relatively rare, since, for a long time, the lesions that were so diagnosed were in fact focal cemento-osseous dysplasias $[1,2,4]$.

It is believed that this benign tumor has an odontogenic origin or is derived from multipotent mesenchymal cells of the periodontal ligament, which are able to form calcified tissues, such as bone and cementum, that are often present in the toothed portion of the maxilla and mandible [5-7,9].

Some authors recognize that, although this lesion is often confined to the jaws, very similar lesions have also been reported in the long bones In this respect, microscopically identical neoplasms with cementum-like differentiation have been found in other sites, such as the orbit, frontal bone, zygomatic bone, ethmoid bone, sphenoid bone, temporal bone, and tibia [1].

Chromosomal abnormalities have been identified in cases of OF, as have mutations in the HRPT2 tumor suppressor gene in patients with a rare condition known as hyperparathyroidism-jaw tumor syndrome, which is characterized by parathyroid adenomas or carcinomas, $\mathrm{OF}$ in the gnathic bones, renal cysts, and Wilms' tumors [10].

Possible triggering factors for the occurrence of $\mathrm{OF}$ have also been considered, including local trauma-induced stimulation, tooth extraction, periodontal disease $[2,6,8,11]$, and even impaired bone maturation of congenital origin (12). Within this context, however, the theory of the origin of OF remains an open question [1].

OF can occur at any age, but is more common in the third and fourth decades of life [1-6,11]. In a review of published cases, the mean age of patients with OF was 25-26 years [2]. This tumor is more frequent in women [2-5,11], with a predilection for the mandible, where the most common site of involvement is the molar/premolar region [2-6]. Although most studies indicate a higher prevalence in women, there are data that appear to show the opposite, such as those of a recently published 10 -year retrospective analysis, which reported a prevalence rate of $56 \%$ in men [12].

OF is a well-circumscribed lesion, allowing relatively easy separation of the tumor from the bone bed. Small lesions are rarely symptomatic, and most cases are diagnosed only radiographically. After reaching a larger size, OF causes a painless expansion of the affected bone, which may lead to facial asymmetry. However, local pain and paresthesia are rare manifestations $[1,2,11,13,14]$. According to a systematic review conducted in $2009,31 \%$ of OF cases are found incidentally [4]. In many cases, OF is identified with routine dental radiographs. Cosmetic complaints and complaints of malocclusion are early clinical manifestations, while facial swelling (asymmetry) is the first symptom observed in $66 \%$ of cases. In $84 \%$ of cases, OF presents with buccolingual expansion of the mandible. When the tumor is located in the maxilla, $90 \%$ of cases involve the maxillary sinus $[2,4]$.
Most OFs grow relatively slowly $[1,3,11,14]$ and, due to the slow growth, the cortical plates of the bone and the overlying mucosa are often intact. However, episodes of cortical plate perforation have also been reported for this type of tumor $[1,13]$. Lesion size can range from 0.2 to $15 \mathrm{~cm}[1,5,8]$.

OF may cause root divergence and even resorption in teeth associated with the lesion. When located in the mandible, it often causes a characteristic downward displacement of the lower border of the mandible [4-6]. Tooth displacement and root resorption are common findings, with increased tooth displacement being considered an early sign. Root divergence is found in approximately $17 \%$ of cases, while the frequency of root resorption ranges from 11 to $44 \%[1,8]$. It is worth noting that some authors consider root divergence and resorption to be uncommon findings. Even in the presence of root resorption, pulp vitality is usually preserved [8].

OF is characterized by a relatively avascular fibrous stroma with a mixture of reticular bone trabeculae and cementum-like spherules $[1,2,4,13]$. The fibrous tissue exhibits varying degrees of cellularity, while the mineralized tissue may appear as bone or osteoid trabeculae, as rounded cell-poor basophilic cementicles, or even as a mixture of the two patterns of hard tissue formation. Bone trabeculae may vary in size and often appear as a mixture of immature and lamellar bone $[1,2]$.

OF usually contains abundant osteoclasts and osteoblasts. Osteoblastic rimming and peripheral osteoid are generally present, and the cementum-like spherules often demonstrate peripheral brush borders blending into the surrounding connective tissue $[1,2]$.

Although only a few lesions are encapsulated, i.e., showing grossly and microscopically a fibrous capsule surrounding the tumor, they are generally well demarcated, with clear boundaries that distinguish damaged tissue from normal tissue [12]. There are currently no histopathological features that can determine the aggressive potential of these lesions or their tendency to recur [2].

Radiographically, OF presents as a well-defined unilocular lesion, often with a sclerotic border but without perforation of the buccal cortical plate [1]. A multilocular presentation may be observed, often as radiolucent lesions with radiopaque foci $[5,12]$. However, some studies have reported that the most common presentation of $\mathrm{OF}$ is as completely radiolucent lesions in $53 \%$ of cases vs. radiolucent areas with radiopaque foci in $40 \%$ of cases $[2,5]$.

Although OF may be completely radiolucent, there is usually evidence of varying degrees of radiopacity depending on the type or amount of calcified material produced in the tumor. Strongly radiopaque lesions with only a thin peripheral radiolucent rim are uncommon, as these features are typically attributed to the final stage of focal cementoosseous dysplasia $[1,2,4]$.

The differential diagnosis of OF is primarily with fibrous dysplasia, as they share clinical, radiographic and 
histopathological features $[1,3,5,8]$. The well-defined clinical and radiographic features of OF as well as the ease of separation of the tumor from normal bone can be considered the main features distinguishing OF from fibrous dysplasia. Many authors state that the difference between OF and fibrous dysplasia is the presence of a fibrous capsule in OF. However, some authors argue that lesions may or may not be surrounded by a fibrous capsule $[1,4]$.

OF contains abundant osteoblasts and osteoclasts and shows a pattern with more regular and less collagenous bone trabeculae, with fewer vascular elements and more cellular elements than fibrous dysplasia [14]. Other authors point out that fibrous dysplasia shows a more uniform pattern of bone differentiation, with trabeculae histologically resembling "Chinese characters", and often affects patients at an earlier age, whereas OF shows a wide variation in the type of mineralized material within the lesion $[1,2]$.

An important factor in the differentiation of these two conditions is the recurrence rate of approximately $25 \%$ for fibrous dysplasia vs. the low recurrence rate reported for OF [3]. In addition to fibrous dysplasia, the differential diagnosis should also include focal cementoosseous dysplasia, periapical cemento-osseous dysplasia, osteoblastoma, desmoplastic fibroma, cementoblastoma, and osteoid osteoma $[2,5]$.

A definitive diagnosis of OF requires correlation of clinical, radiographic and microscopic findings - the diagnosis should be guided by clinical and radiographic findings and confirmed histopathologically $[2,3,5]$.

The circumscribed and well-defined nature of OF often allows enucleation of the lesion and relatively easy separation of the tumor from the bone bed. In cases of high growth rate and consequent considerable destruction of bone tissue, surgical resection might be necessary with or without bone grafting [1].

In general, there are 3 treatment options: enucleation, curettage, and surgical resection. Enucleation is indicated for small, well-defined lesions. Curettage should be used in relatively large lesions with well-defined borders but without involvement of the mandibular basal bone or perforation of the cortical plate. Resection, in turn, is indicated for aggressive cases with rapid growth, involvement of basal bone or perforation of the cortical plate $[2,3,13,15]$. As a general rule, enucleation and curettage are the first options, followed by partial resection or en bloc resection to reduce the likelihood of recurrence [5].

If enucleation results in a large surgical cavity or if extensive surgical resection is required, additional reconstruction with bone grafts and osseointegrated implants may be necessary to meet the aesthetic and functional needs of the patient, especially when teeth are removed along with the lesion [1]. In cases of segmental resection of the mandible $(\leq 5 \mathrm{~cm})$, reconstruction with an autogenous iliac crest bone graft is indicated. In cases involving larger defects $(>5 \mathrm{~cm})$, a microvascular graft should be used [5].
The prognosis of OF is good, with rare episodes of recurrence and no evidence of malignant transformation $[3,13,15]$. In a clinical study of 14 cases, in which patients were followed for up to 18 years after treatment, the recurrence rate was extremely low for all types of surgical intervention [15]. However, some authors recommend the use of radical resection because of the tendency for recurrence and possibility of malignant transformation. There are reports that up to $12 \%$ of cases recurred or were reactivated, a clinically significant rate that supports the need for long-term clinical and radiographic follow-up $[2,4,5]$.

In conclusion, OF is a benign fibro-osseous tumor of the craniofacial bones commonly involving the jaws, especially the mandible. The diagnosis is based on a combination of clinical, radiographic and histologic criteria. Radiographically, OF usually appears as a well-defined mixed lesion, i.e., as a radiolucent area with well-defined margins containing radiopaque foci.

Currently, there is controversy about the recurrence rate - while some authors consider it to be extremely low, others report it to be relatively high. Nonetheless, there is consensus that early diagnosis and longitudinal follow-up of this type of tumor is essential for a good prognosis. It is also worth noting the importance of making a differential diagnosis with other lesions, especially fibrous dysplasia, before defining the most appropriate approach for each case. Conservative treatment is an effective option that reduces morbidity and simplifies postoperative rehabilitation.

Finally, we emphasize the importance of properly documenting individual cases and interpreting postoperative radiographic images along with the patients in order to avoid possible confusion between areas of bone repair and of potentially suspicious lesions in the future.

\section{REFERENCES}

1. Paiva JG, Böing F, Benaglia MB, Nascimento A. Fibroma ossifying: report of 2 cases. Rev Cir Traumatol Buco-Maxilo-fac. 2009;9:33-40.

2. Gondivkar SM, Gadbail AR, Chole R, Parikh RV, Balsaraf S. Ossifying fibroma of the jaws: report of two cases and literature review. Oral Oncol. 2011;47:804-9. https://doi.org/10.1016/j.oraloncology.2011.06.014

3. Trijolet JP, Parmentier J, Sury F, Goga D, Mejean N, Laure B. Cementoossifying fibroma of the mandible. Eur Ann Otorhinolaryngol Head Neck Dis. 2011;128:30-3. https://doi.org/10.1016/j.anorl.2010.06.005

4. MacDonald-Jankowski DS. Ossifying fibroma: a systematic review. Dentomaxillofac Radiol. 2009;38:495-513. https://doi.org/10.1259/ dmfr/70933621

5. Saikrishna D, Shetty S, Ramya S. Massive ossifying fibroma of mandible Ann Maxillofac Surg. 2014;4:81-4. https://doi.org/10.4103/22310746.133075

6. Vura NG, Gaddipati R, Ramisetti S, Kumara R, Reddy R, Kanchi U. Surgical Management of Ossifying Fibroma in Maxilla: Report of Two Cases. J Int Oral Health. 2015;7:115-8

7. Canger EM, Celenk P, Kayipmaz S, Alkant A, Gunhan O. Familial ossifying fibromas: report of two cases. J Oral Sci. 2004;46:61-64. https://doi. org/10.2334/josnusd.46.61

8. Perez-Garcia S, Berini-Aytes L, Gay-Escoda C. Ossifying fibroma of the upper jaw: report of a case and review of the literature. Med Oral. 2004;9:333-9.

9. Pinos AJSP, Gaya MVO, Sánchez EP, Capilla MV. Fibroma óseo juvenil: a propósito de un caso clínico. Med Oral Patol Oral Cir Bucal. 2004 9:454-8. 
10. Pimenta FJ, Silveira LFG, Tavares GC, Silva AC, Perdigão PF, Castro WH, et al. HRPT2 gene alterations in ossifying fibroma of the jaws. Oral Oncol. 2006:42:735-9. https://doi.org/10.1016/j.oraloncology.2005.11.019

11. Martin-Granizo R, Sanchez-Cuellar A, Falahat F. Cemento-ossifying fibroma of the upper gingivae. Otolaryngol Head Neck Surg. 2000;122:775. https:// doi.org/10.1067/mhn.2000.103078

12. Tchane IB, Adjibabi W, Biaou O, Hounkpe Y. Cemento-ossifying fibroma: two cases. Rev Stomatol Chir Maxillofac. 2005;106:30-2.

13. Mohanty S, Gupta S, Kumar P, Sriram K, Gulati U. Retrospective Analysis of Ossifying Fibroma of Jaw Bones Over a Period of 10 Years with Literature Review. J Maxillofac Oral Surg. 2014;13:560-7. https://doi.org/10.1007/ s12663-013-0545-0
14. Yoshimura H, Ohba S, Nakamura M, Sano K. Mandibular reconstruction using iliac bone and great auricular nerve grafts and oral rehabilitation using osseointegrated implants in a patient with a large ossifying fibroma: a 10-year follow-up study. J Oral Maxillofac Surg. 2013;71:2176-88. https:// doi.org/10.1016/j.joms.2013.04.034

15. Triantafillidou K, Venetis G, Karakinaris G, lordanidis F. Ossifying fibroma of the jaws: a clinical study of 14 cases and review of the literature. Oral Surg Oral Med Oral Pathol Oral Radiol. 2012;114:193-9. https://doi. org/10.1016/j.tripleo.2011.07.033 